\title{
Quadratic Support Vector Machine For The Bomba Traditional Textile Motif Classification
}

\author{
Nuraedah', Muhammad Bakri', Anita Ahmad Kasim ${ }^{3}$ \\ ${ }^{1}$ Department of History, Faculty of Teaching and Education, Universitas Tadulako Palu, Indonesia \\ ${ }^{2}$ Department of Architecture, Faculty of Engineering, Universitas Tadulako, Indonesia \\ ${ }^{3}$ Department of Information Technology, Faculty of Engineering, Universitas Tadulako, Indonesia
}

\begin{tabular}{l}
\hline Article Info \\
\hline Article history: \\
Received Feb 19, 2018 \\
Revised Apr 21, 2018 \\
Accepted May 17, 2018 \\
\hline
\end{tabular}

\section{Keywords:}

Batik bomba

Feature

Pattern recognition

Quadratic SVM

\begin{abstract}
The Bomba textile is one of the textile fabrics in Indonesia used in a province called Sulawesi Tengah. Bomba Textile has a unique pattern and has a philosophical meaning in human life in Sulawesi Tengah. Bomba Textile has many motif patterns and varied colors. The problem in this research is the difficulty in classifying every The Bomba textile motif in each class. Data classification is needed to recognize the motif of each Bomba textile pattern and to cluster it into the appropriate class. The features used to classify the Bomba textile motif is the textural feature. Texture features obtained from Gray-Level Co-occurrence matrices (GLCM) method consisting of energy, contrast, homogeneity and correlation with four angles $0 \square, 45 \square, 90 \square$, and $135 \square$. This research will implement Quadratic Vector Machine (QSVM) method with texture feature on Bomba textile pattern. The use of a single texture feature with angles $90 \square$ has an accuracy of $90.3 \%$. The incorporation of texture features by involving all features at all angles can improve the accuracy of the classification model. This research produces a model of motif classification on the Bomba textile which has the classification accuracy of $94.6 \%$ and error rate of $5.4 \%$.
\end{abstract}

Copyright (ㅇ 2018 Institute of Advanced Engineering and Science. All rights reserved.

\section{Corresponding Author:}

Anita Ahmad Kasim,

Department of Information Technology, Faculty of Engineering,

Universitas Tadulako, Indonesia.

Email: nita.kasim@gmail.com

\section{INTRODUCTION}

Almost every region in Indonesia has a distinctive traditional cloth. In Sulawesi Tengah, there is a tradition textile called Bomba textiles. Bomba textiles are inspired by traditional textiles of Sulawesi Tengah. Since 2008, Bomba Textiles began to be developed into a local handicraft industry and was introduced as one of the city icons. Along with the development of technology and textile technology, Bomba textile industry develops with various motifs without leaving the original motive with the live philosophy in every motif. Bomba textile motif consists of the Sero Putus motif, the Sero Tangga motif, the Bunga Ronto Motif, the Rumput Laut motif, the Warsala motif, the Sero Bunga motif and the Sero Ketupat Motif. There are difficulties in classifying every Bomba textile motif. Previous research has classified Bomba textile motif using Linear Support Vector machine (LSVM) method and yielded good accuracy of 77.14\% [1]. The problem ini this research is how to classify the motif of each Bomba textile into appropriate class. Currently, various researches have been conducted on the classification and pattern recognition of textile motifs in various regions of Indonesia such as the pattern of batik pattern in Pulau Jawa, the classification of batik pattern of Besurek in Pulau Jambi and some other patterns of textile pattern recognition in Indonesia [2], [3]. Classification methods on the pattern recognition of batik motifs have been widely used among with the Scale Invariant Feature Transform (SIFT) approaches, Artificial Neural Network, Linear Support Vector Machine, Canny Detection, GLCM and and others [4]-[7]. This is a way to preserve Indonesian culture 
especially for Batik Indonesia. This research will describe the process of classification of Bomba textile motif with Quadratic Support Vector Machine (QSVM) method. The classification phase begins with the acquisition of Bomba textile motif image in the form of the digital image, pre-processing, texture feature extraction and classification with Quadratic Vector Support Quadratic (QSVM).

This paper consists of five parts: the first part is the introduction, the second part is the literature review, the third part is the proposed model, part four is the result of the discussion and the last is the conclusion and the next work.

\section{LITERATURE REVIEW}

Textile motifs can be classified using pattern recognition methods. Pattern recognition methods are one of the areas in computer science, which maps data into a particular concept. This particular concept is called a class or category. Various methods are known in pattern recognition, such as linear discrimination analysis, hidden markov model, artificial intelligence methods such as artificial neural networks and support vector machines [8]. Textile motifs can be classified with recognizing the visual characteristics from the textile. The visual characteristics called the feature of the textile. The textile motifs have some feature that can distinguish the textile motif pattern to another one. The textile motif feature is obtained by various methods of extraction. There are three developments of methods of extraction feature i.e. the color feature extraction for the color feature, the texture feature extraction for the texture feature and the shape feature extraction methods for the shape feature [9]. This research limited only the texture feature for textile motif classification.

The texture is a useful feature for images with large areas in human visualization s ystems [10], [11]. The textures feature used to recognize an object. Several studies in recognizing textile patterns have been widely developed in Indonesia. The results of that research become the reference in solving problems in the classification of the Bomba textile.

The process before extract the feature called the preprocess. The preprocess consist of the grayscale image transformation, resize the images, and the segmentation of images [12]-[14]. In general, the way to extract texture features in images is divided into 2 based on the spatial texture and the s pectral texture. The characteristic of spatial texture is obtained by finding local pixel structures in the original image. The characteristic spectral texture is obtained by transforming into the frequency domain and calculating the characteristics of the transformed image [15]. The texture feature extraction method is used to identify the image of the batik. The Texture feature was obtained by extracting pixel values frombatik images that have a grayscale transformation process and canny detection [16]. Another texture feature extraction method used is characteristic extraction with Daubechies type 2 level 2 wavelet transformation to process texture feature consisting of standard deviation, mean and energy. A method of classical batik that can classify the batik motif automatically into the subclass based on the shape ornament of texture. Some features obtained through the approach of batik image texture analysis using a statistical approach is the entropy, the correlation, the energy, and the homogeneity [17], [18].

The artificial neural network is used to classify the image based on the pattern. Furthermore, the Rotate Wavelet Filter is used for extraction of classified the batik features [19], [20]. An experiment was conducted several times on different batik images to get an idea of the quality of the use of combining the features of Discrete Wavelet Transform and the feature of Gray Level Co-Occurrence Matrices (GLCM) in the recognizing of multi label patterns [21]. Wavelets are used to obtain the texture feature from batik images. The way to obtain the texture feature by defining the multi-resolution space generating energy features and standard deviations. The size of batik images is $128 \times 128$ pixel. The research on batik is done by adding Discrete Wavelet Transform characteristic and characteristic of Gray Level Co-Occurrence Matrices (GLCM).

The accuracy of the Batik textile recognition with Gabor feature as the texture feature is $59.74 \%$. The feature of the histogram has an accuracy of $48.05 \%$, only able to recognize 37 images of 77 known batik images. Number edge features have a higher accuracy of the two previous features of $66.25 \%$, able to recognize 51 images of 77 images of batik. The combination of two features of Gabor and the number edge increases an accuracy of $64.94 \%$. It is able to recognize 50 images of 77 images [21], [22]. Intelligent system for the Batik textile classification with feature extraction and classification performed on batik image have high identification accuracy. Image recognition is done by finding the closest distance of test data image to target data image. The amount of distance obtained then sought the minimum distance or closest distance. From the results of the closest distance is the image of the batik textile patterns can be classified and identified in accordance with the group [23].

In image classification required rules in the class of each image. The rules can be obtained by heuristic fuzzy decision tree approach on entropy value [24]. The Batik textile can classified by artificial 
neural network [25]. There are other methods that can be used for the classification and recognition of textiles besides artificial neural networks. One of the methods in machine learning is the Support Vector Machine (SVM) method [26]. The Support Vector Machine (SVM) was first introduced by Vapnik in 1992 as a learning concepts for classification the field of pattern recognition. The evaluation of the ability in various applications places the SVM as the state of the art in pattern recognition, and to day is one of the fastest-growing themes. SVM is a learning machine method that works on the principle of Structural Risk Minimization (SRM) in order to find the best hyperplane that separates the two classes in the input space. Some research that has been done in connection with pattern recognition with SVM is to classify textile motifs of fabrics. SVM development used can perform multi-tasks to recognize patterns of multiple images that are processed through the separation of each characteristic value with a hyperplane by programming of Quadratic SVM method is expected to increase the accuracy of pattern recognition [27]-[29].

\section{RESEARCH METHODS}

In this research, we propose a model that will be used to classify the Bomba textile motif with Quadratic Support Vector Machine (QSVM) based on the texture feature. The model has four phase to classify the Bomba Textile consist of the acquisition phase, the preprocess phase, the feature extraction phase and the last phase is classification phase. The phases of classification in this study are shown in Figure 1.

Figure 1The image acquisition phase is the phase to get the image of the Bomba textile by camera. The images processed in the preprocess that consists of two stages of resizing the image to $256 \times 256$ pixels and transforming the image to an image with gray level. The Bomba textile data obtained from the acquisition of the Bomba textile image consist of seven kinds of the Bomba textile motifs i.e. the Sero Putus motif, the Sero Tangga motif, the Bunga Ronto Motif, the Rumput Laut motif, the Warsala motif, the Sero Bunga motif and the Sero Ketupat Motif.The result of the acquisition image can be seen in Figure 2.

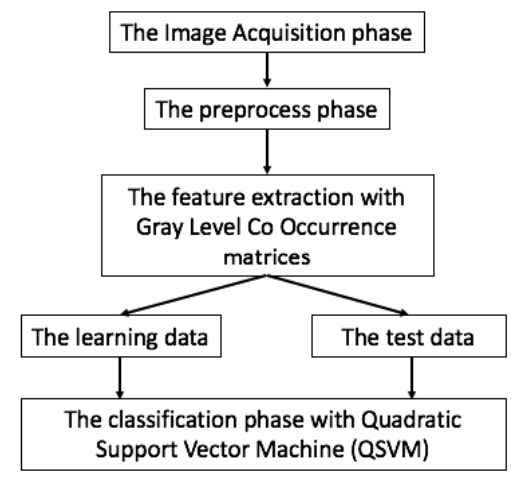

Figure 1. The phases of classification for the bomba textile classification

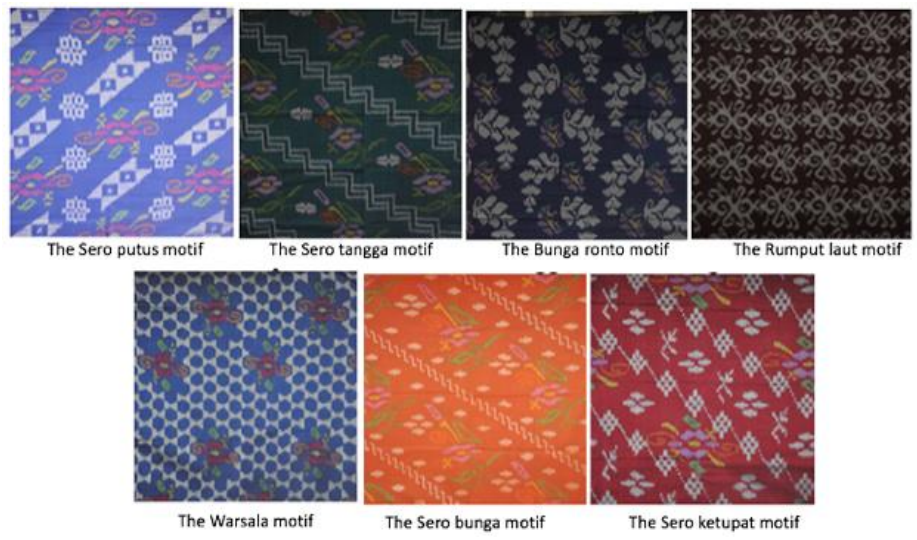

Figure 2. The result of acquisition of the bomba textile image motif 
The Bomba textile image with gray levels will be the image that is extracted the value of its features. The result of the image transformation to gray scale can be seen in Figure 3. Extraction of values used as a characteristic image of Bomba textile motif using Gray Level Co-occurrence matrices method. GLCM is a method for obtaining texture features by calculating the probability of an adjacency relationship between two pixels at a certain distance and angle orientation [30].

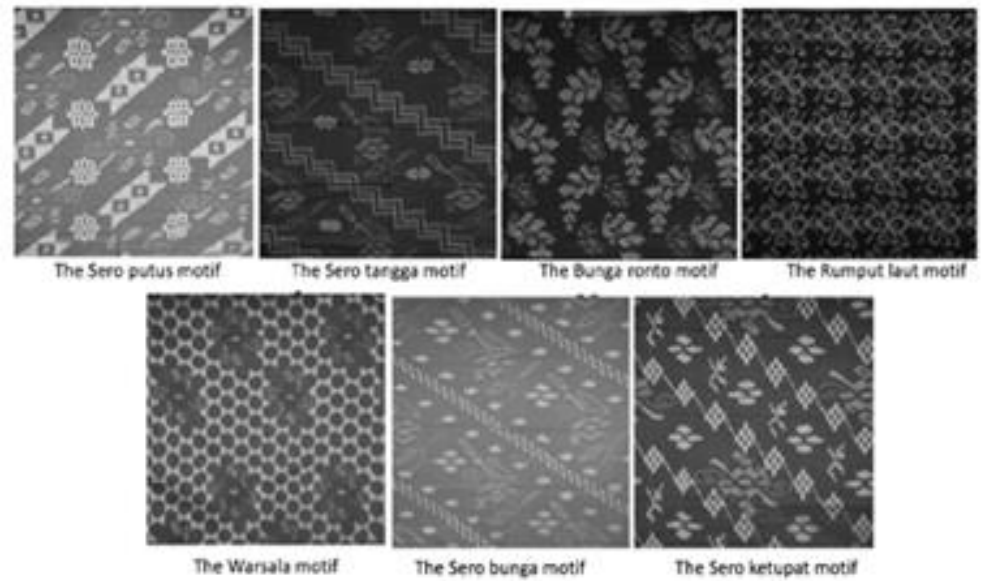

Figure 3. The result of the image transformation to gray scale

The orientation formed in four orientation with angle $45^{\circ}$ i.e. $0^{\circ}, 45^{\circ}, 90^{\circ}$, and $135^{\circ}$. GLCM is matrices with the number of rows and columns equal to the number of gray levels in the image. Four features to be extracted in this study based on texture features that have been proposed by Haralick et al in 1973, namely energy, contrast, homogeneity and correlation [31].

1. Energy by (1).

Homogeneity of an image can be measured by the energy feature. The energy can be calculated

$$
\text { Energy }=\sum_{i=0}^{G-1} \sum_{j=0}^{G-1}\{P(i, j)\}^{2}
$$

\section{Contrast}

Variation in local intensity is contrast. It will contribute to $\mathrm{P}(\mathrm{i}, \mathrm{j})$ of the diagonal i.e. $i=j$. The contrast of an image can be calculated by (2).

$$
\text { Contrast }=\sum_{n=0}^{G-1} n^{2}\left\{\sum_{i=1}^{G} \sum_{j=1}^{G} P(i, j)\right\},|i-j|=n
$$

\section{Homogeneity}

The homogeneity feature is strongly influenced by the homogeneity of the image, due to the weight factor of $(1+(\mathrm{i}-\mathrm{j}) 2)-1$. The homogeneity feature will gain a small contribution from the homogeneity area $\mathrm{i}=\mathrm{j}$. To calculate Homogeneity uses (3)

$$
\text { Homogenitas }=\sum_{i=0}^{G-1} \sum_{j=0}^{G-1} \frac{1}{1+(i-j)^{2}} P(i, j)
$$

\section{Correlation}

The measure of the dependent linear gray level between pixels at the relative position of each pixel is the correlations feature. Correlations can be calculated based on (3) as follows: 


$$
\text { Correlation }=\sum_{i=0}^{G-1} \sum_{j=0}^{G-1} \frac{\{i \times j\} \times P(i, j)-\left\{\mu_{x} \times \mu_{y}\right\}}{\sigma_{x} \times \sigma_{y}}
$$

The texture feature value is obtained by (1), (2), (3) and (4), where $G(i, j) \mathrm{G}(\mathrm{i}, \mathrm{j})$ is the number of times the pixel with the gray level $i$ occurs alongside the gray level $\mathrm{j}$ and $\mathrm{n}$ is the number of pairs pixels. $P(i, j) \mathrm{P}(\mathrm{i}, \mathrm{j})$ is the joint probability distribution of the pixel pair with the gray level $\mathrm{i}$ and the gray level $\mathrm{j}$ which can be calculated by dividing $P(i, j) \mathrm{P}(\mathrm{i}, \mathrm{j})$ by $\mathrm{n}[31]$. The feature extraction process can be seen in Figure 4. The final stages of the process of image classification of Bomba textile motif is to classify the value of texture feature of Bomba textile motif image with QSVM method. Quadratic SVM is the development of the SVM method used for nonlinear multiclass data classification.

The basic principle of SVM is linear classifier, and further developed to work on nonlin ear problems by incorporating kernel trick concepts in high-dimensional workspaces. This development provides a stimulus of research interest in the field of pattern recognition for investigating the potential of SVM capabilities. The SVM concept can be explained simply as a method of finding the best hyperlane.

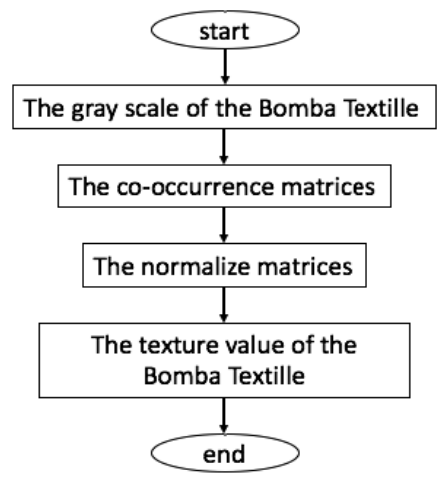

Figure 4. The feature extraction process

The method of the Supprt Vector Machine can be seen in Figure 5 Hyperlink serves to separate the two classes on the input data. Figure 5a shows data from two classes that are class 1 data and class 0 data symbolized by blue boxes and green circles. The classification problem can be solved by classification method with SVM. It is done by finding a line that can separate the two groups of data. The best separator hyperplane can be obtained by measuring the hyperplane margins and their maximum points. Margin is the distance between the hyperplane and the closest data from each class. The data closest to the best hyperplane is called Support Vector. The solid line in Figure 5b shows the best hyperplane. Hyperplane is best located right in the second class. The data obtained in classification is not linear but there are several classes whose groupings are not linear.

The nonlinear problem can be solved by modified SVM. SVM is modified by entering the Kernel function. Kernels aim to make linear models work on nonlinear models. To make a linear model nonlinear is done by mapping to a higher dimension. This will change the data representation. Each example defines by two features as (5).

$$
x=\left\{x_{1}, x_{2}\right\}
$$

There is no linear separator exists for this data in (5). To make a linear model nonlinear each example mapped as (6).

$$
x=\left\{x_{1}, x_{2}\right\} \rightarrow z=\left\{x_{1}{ }^{2}, \sqrt{2} x_{1}, x_{2}, x_{2}{ }^{2}\right\}
$$

Now the data has three features and becomes linearly separable in the new representation. The change of the data representation can be seen in Figure 6. 

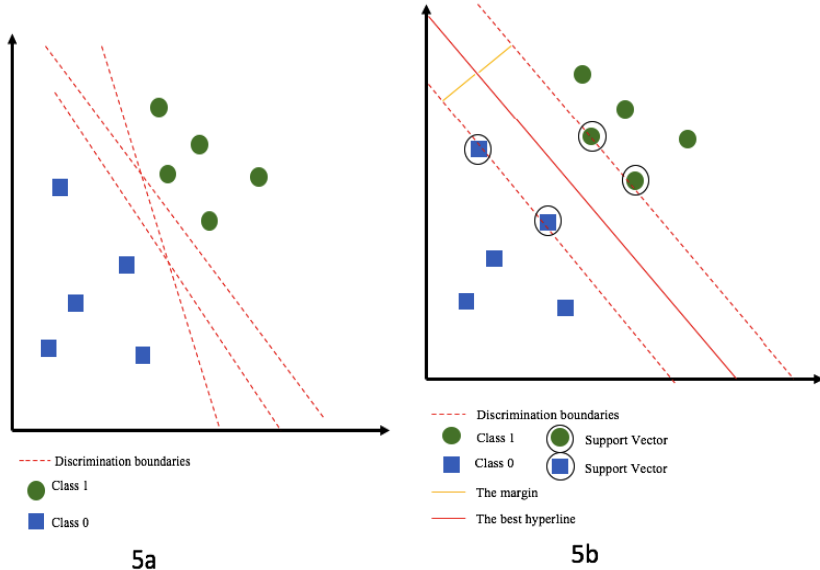

Figure 5. Support Vector Machine
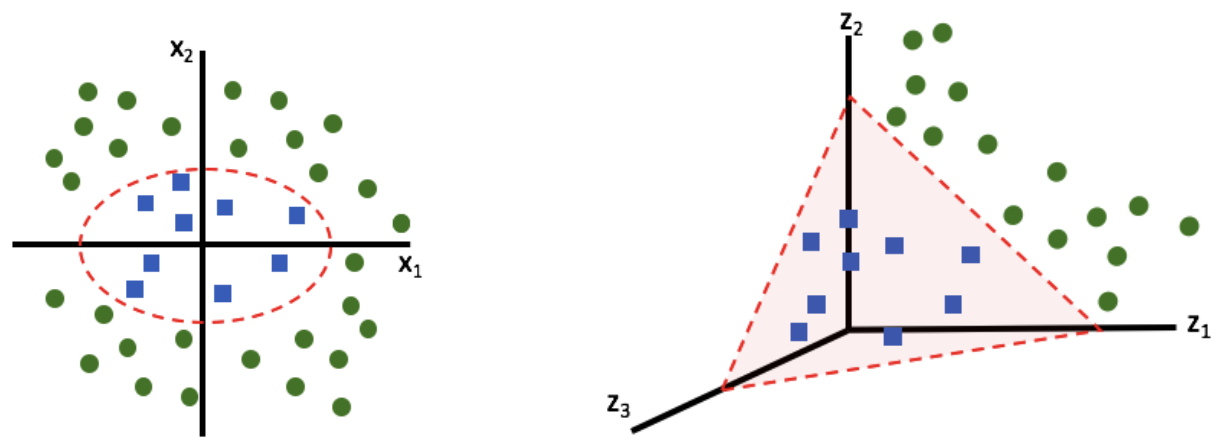

Figure 6. The data representation

Consider the following mapping $\varnothing$ for an example in (7).

$$
x=\left\{x_{1}, \ldots, x_{D}\right\}
$$

Each new feature uses a pair of the original feature. It is an example of a quadratic problem $\emptyset: x \rightarrow$ $\left\{x_{1}{ }^{2}, x_{2}{ }^{2}, \ldots, x_{D}{ }^{2}, x_{1} x_{2}, \ldots, x_{1} x_{D}, \ldots, x_{D-1} x_{D}\right\}$ Consider two example $x=\left\{x_{1}, x_{2}\right\}$ and $z=\left\{z_{1}, z\right\}$. The function $k$ (kernel) that takes as inputs $x$ and $z$ can be calculated by (8).

$$
\begin{aligned}
& k(x, z)=\left(x^{\top} z\right)^{2} \\
& =\left(x_{1} z_{1}+x_{2} z_{2}\right)^{2} \\
& \begin{aligned}
=x_{1}{ }^{2} z_{1}{ }^{2} & +x_{2}{ }^{2} z_{2}{ }^{2}+2 x_{1} x_{2} z_{1} z_{2} \\
= & \left(x_{1}{ }^{2}, \sqrt{2 x_{1} x_{2}}, x_{2}{ }^{2}\right)^{\top}\left(z_{1}{ }^{2}, \sqrt{2 z_{1} z_{2}}, z_{2}{ }^{2}\right) \\
= & \emptyset(x)^{\top} \emptyset(z)
\end{aligned}
\end{aligned}
$$

$k$ defines a mapping $\emptyset$ to higher dimensional space as (9).

$$
\emptyset(x)=\left\{x_{1}^{2}, \sqrt{2 x_{1} x_{2}}, x_{2}{ }^{2}\right\}
$$

The simple definition of kernel is a certain way to gives a higher dimension by mapping $\emptyset$. Moreover the kernel $k(x, z)$ also computes the dot product $\emptyset(x)^{\top} \emptyset(z)$

Each kernel $k$ has associated feature mapping $\emptyset$. $\emptyset$ takes input $x \in X$ (input space) and maps it to $F$ (feature space). Kernel $k(x, z)$ takes two input and gives their similarity in $F$ space. The mapping shown in (10) and (11).

$$
\emptyset: X \rightarrow F
$$




$$
k: X \rightarrow X \rightarrow \mathbb{R}, k(x, z)=k(x, z)^{T} \emptyset(z)
$$

The kernel function $\mathrm{k}$ also defines the Kernel Matrix $\mathrm{K}$ over the data. Given $\mathrm{N}$ examples $\left\{x_{1}, x_{2}, \ldots, x_{n}\right\}$, the $(i, j)$-th entry of $\mathrm{K}$ is defined as (12).

$$
K_{i j}=k\left(x_{i}, x_{j}\right)=\emptyset\left(x_{i}\right)^{\top} \emptyset\left(x_{j}\right)
$$

description:

$K_{i j} \quad:$ Similarity between the $i$-th and the $j$-th example in the feature $F$ space.

$K \quad: N x N$ matrix of pairwise similarity between example in $F$ space.

$K$ is a symmetric and positive definite matrix.

The following are the most popular kernels for real-valued vector inputs can be seen at (12)-(15).

1. Linear Kernel

$$
k(x, z)=x^{\top} z
$$

2. Quadratic Kernel

$$
k(x, z)=\left(x^{\top} z\right)^{2}=\left(1+x^{\top} z\right)^{2}
$$

3. Polynomial Kernel (of degree d)

$$
k(x, z)=\left(x^{\top} z\right)^{d}=\left(1+x^{\top} z\right)^{d}
$$

4. Radial Basis Function

$$
k(x, z)=\exp \left[-\gamma\|x-z\|^{2}\right]
$$

In this research, we use the quadratic kernel to classify the textile Bomba into the class of the Bomba textile. All images of the Bomba textile process with co-occurrence matrices approach and classified with Support Vector Machine Method with quadratic kernel. It is call as Quadratic Support Vector Machine (QSVM).

\section{RESULT AND DISCUSSION}

Texture features extracted from the Bomba textile image are contrast, correlation, energy and homogeneity with the angle of each feature $0^{\circ}, 45^{\circ}, 90^{\circ}$ and $135^{\circ}$. The extracted feature will be in the input class taken 5 data as test data, so that obtained 93 train data and 35 test data.

The classification process begins with the training phase on motif trained data based on texture features at angles $0^{\circ}, 45^{\circ}, 90^{\circ}$ and $135^{\circ}$. The data classified with the QSVM by adding the quadratic kernel to the Bomba textile classification. The results of training on motifs based on texture features with each angle $0^{\circ}, 45^{\circ}, 90^{\circ}$ and $135^{\circ}$ then tested using test data that has been prepared.

The classification accuracy obtained from the result of the true data output from the model compared with target data for the model. The correct amount of data matching the outputs and targets is indicated by the confusion matrices. The confusion matrices show in

Table 1. Accuracy, precision, recall and error rate value is obtained by the formula (17), (18), (19) and (20).

Table 1. The Confusion Matrices

\begin{tabular}{llcc}
\hline \multicolumn{2}{l}{ Confusion Matrices } & \multicolumn{2}{c}{ Output Class } \\
& Positive & Negative \\
\hline \multirow{2}{*}{ Target Class } & Positive & True Positive (TP) & False Positif (FP) \\
& Negative & False Negative (FP) & True Negative (TN) \\
\hline
\end{tabular}


1. Accuracy

$$
\text { Accuracy }=\frac{T P+T N}{P+N}
$$

2. Precision

$$
\text { Precision }=\frac{T P}{T P+F P}
$$

3. Recall

$$
\text { Recall }=\frac{T P}{T P+F N}
$$

4. Error rate

$$
\text { Error Rate }=(1-\text { Acc })
$$

In this research, we have seven class of The Bomba textile. The confusion matrices modified as a

\begin{tabular}{|c|c|}
\hline iption: & \\
\hline ero Putus motif & ala mo \\
\hline C2: The Sero Tangga motif & C6: The Sero Bunga motif \\
\hline
\end{tabular}
multiclass confusion matrices for classification as shown in Table 2 [32].

Table 2. The Multiclass Confusion Matrices for the Bomba Textile Classification

\begin{tabular}{llllccccc}
\hline TC=True Class & & \multicolumn{7}{c}{ Output Class } \\
FC=False Class & & C1 & C2 & C3 & C4 & C5 & C6 & C7 \\
\hline \multirow{4}{*}{ Target Class } & C1 & TC1 & FC1 & FC1 & FC1 & FC1 & FC1 & FC1 \\
& C2 & FC2 & TC2 & FC2 & FC2 & FC2 & FC2 & FC2 \\
& C3 & FC3 & FC2 & TC3 & FC3 & FC3 & FC3 & FC3 \\
& C4 & FC4 & FC4 & FC4 & TC4 & FC4 & FC4 & FC4 \\
& C5 & FC5 & FC5 & FC5 & FC5 & TC5 & FC5 & FC5 \\
& C6 & FC6 & FC6 & FC6 & FC6 & FC6 & TC6 & FC6 \\
& C7 & FC7 & FC7 & FC7 & FC7 & FC7 & FC7 & TC7 \\
\hline
\end{tabular}

C4: The Rumput Laut motif

The accuracy, the precision, the recall and the error calculated by (21), (22), (23) and (24) based on the multiclass confusion matrices on Table 3.

1. Accuracy

$$
\text { Accuracy }=\frac{T C 1+\cdots+T C 7}{C 1+\cdots+C 7} \times 100 \%
$$

2. Precision

$$
\text { Precision }=\frac{T C}{\text { Target Class True }} \times 100 \%
$$

3. Recall

$$
\text { Recall }=\frac{T C}{\text { Output Class True }} \times 100 \%
$$

4. Error rate

$$
\text { Error Rate }=(100-\text { Accuracy })
$$


The extracted feature will be taken five data as test data, so that obtained ninety-three data as the training data and thirty-five data as the testing data. In training phase, ninety-three data in training data classified by QSVM. Table 3 shown the result of training phase for Bomba textile classification for feature with angle $0^{\circ}$.

Table 3. The Training Phase Result of the Bomba Textile Classification

\begin{tabular}{ccccccccc}
\hline TC=True Class & & \multicolumn{7}{c}{ Output Class } \\
FC=False Class & & C1 & C2 & C3 & C4 & C5 & C6 & C7 \\
\hline \multirow{5}{*}{ Target Class } & C1 & 15 & 0 & 0 & 0 & 0 & 0 & 0 \\
& C2 & 0 & 6 & 4 & 0 & 0 & 0 & 0 \\
& C3 & 1 & 0 & 9 & 0 & 0 & 0 & 0 \\
& C4 & 0 & 0 & 0 & 15 & 0 & 0 & 0 \\
& C5 & 0 & 1 & 0 & 0 & 12 & 0 & 0 \\
& C6 & 1 & 1 & 0 & 0 & 0 & 8 & 3 \\
& C7 & 0 & 0 & 0 & 0 & 0 & 0 & 15 \\
\hline
\end{tabular}

The training phase consists of four experiments. The first experiment until the fourth experiment classified by the texture feature in angle $0^{\circ}, 45^{\circ}, 90^{\circ}$ and $135^{\circ}$. The result of classification with texture feature in angle $0^{\circ}, 45^{\circ}, 90^{\circ}$ and $135^{\circ}$ show in Table 4.

Table 4. Accuracy and Error Rate Classification of the Bomba Textile with Angle $0^{\circ}, 45^{\circ}, 90^{\circ}$ and $135^{\circ}$

\begin{tabular}{ccccc}
\multicolumn{5}{c}{ (The Training phase) } \\
\hline Texture feature angle & Recall $(\%)$ & Precision $(\%)$ & Accuracy $(\%)$ & Error Rate $(\%)$ \\
\hline Angle $0^{\circ}$ & 86.78 & 84.51 & 86.02 & 13.98 \\
Angle $45^{\circ}$ & 86.81 & 86.67 & 84.95 & 15.05 \\
Angle $90^{\circ}$ & 86.37 & 86.08 & 84.95 & 15.05 \\
Angle $135^{\circ}$ & 86.99 & 84.80 & 84.95 & 15.05 \\
\hline
\end{tabular}

In testing phase, thirty-five data in testing data classified by QSVM and the result can be seen in Table 5. The testing phase consists of four experiments. The first testing until the fourth experiment classified by the texture feature in angle $0^{\circ}, 45^{\circ}, 90^{\circ}$ and $135^{\circ}$. Accuracy and Error rate with testing data in the Bomba classification textile by using texture feature with each different angle can be seen in Table 5

Table 5. Accuracy and Error Rate Classification of the Bomba Textile with Angle $0^{\circ}, 45^{\circ}, 90^{\circ}$ and $135^{\circ}$ (The Testing Phase)

\begin{tabular}{ccc}
\hline Texture feature angle & Accuracy $(\%)$ & Error rate $(\%)$ \\
\hline Angle $0^{\circ}$ & 86.0 & 14 \\
Angle $45^{\circ}$ & 84.9 & 15.1 \\
Angle $90^{\circ}$ & 90.3 & 9.7 \\
Angle $135^{\circ}$ & 84.9 & 15.1 \\
All Angle & 94.6 & 5.4 \\
\hline
\end{tabular}

The result of classification for each texture feature with various angle of texture feature shows the highest accuracy is texture feature at $90^{\circ}$ angle in the amount of $90.3 \%$ and error rate of $9.7 \%$. The lowest accuracy value at an angle of $45^{\circ}$ and $135^{\circ}$ with an accuracy of $84.9 \%$ and error rate of $15.1 \%$.

Results obtained in previous research using Linear Support Vector Machine method showed classification accuracy based on texture feature at angle $0^{\circ}$ equal to $74.2 \%$, angle $45^{\circ}$ equal to $64.5 \%$, angle $90^{\circ}$ of $66.7 \%$ and $135^{\circ}$ of $67.5 \%$ [1]. The classification at the training stage becomes $80.65 \%$ and in the testing phase produces an accuracy of $77.14 \%$. The incorporation of texture features by involving all features at all angles can improve the accuracy of the classification model. This research produces a model of motif classification on the Bomba textile which has the classification accuracy of $94.6 \%$ and error rate of $5.4 \%$. The comparison of both research results indicates an increase of 13.16\% accuracy using Quadratic Support Vector Machine method. 


\section{CONCLUSION}

The model of the Bomba textile motif classification with QSVM proposed in this research is able to classify the Bomba Kaili motif image with $90.3 \%$ accuracy and $9.7 \%$ error rate. This shows the model of the Bomba textile motif classification with QSVM can be implemented in the Bomba textile application.

To improve the accuracy and yield the lower the error rate on the classification of the Bomba textile, the future works is merging of texture feature of Bomba textilemotif. Furthermore, we will implement this model in the Bomba Motif Classification Application based android system.

\section{ACKNOWLEDGMENT}

The authors wish to thank Directorate of Research and Community Service Directorate General Strengthening Research and Development Ministry of Research, Technology and Higher Education Subject with Contract Research. Number: 106/SP2H/LT/DRPM/IV/2017, April 27th, 2017

\section{REFRENCES}

[1] Nuraedah and M. Bakri, "Klasifikasi Motif Kain Tradisional Batik Bomba Kaili Berdasarkan Fitur Tekstur Citra Digital," in Prosiding Seminar Nasional Sistem Informasi 2017 (SENASIF 2017), 2017, September, pp. 730-738.

[2] A. D. Nugrowati, A. R. Barakbah, N. Ramadijanti, and Y. Setiowati, "Batik Image Search System with Extracted Combination of Color and Shape Features," in International Conference on Imaging and Printing Technologies, 2014.

[3] F. U. Karimah and A. Harjoko, "Classification of Batik Kain Besurek Image Using Speed Up Robust Features (SURF) and Gray Level Co-occurrence Matrix (GLCM)," in Third International Conference, SCDS 2017, 2017, pp. 81-91.

[4] I. Nurhaida, A. Noviyanto, R. Manurung, and A. M. Arymurthy, "Automatic Indonesian's Batik Pattern Recognition Using SIFT Approach,” Procedia - Procedia Comput. Sci., vol. 59, no. Iccsci, pp. 567-576, 2015.

[5] N. Suciati, W. A. Pratomo, and D. Purwitasari, "Batik Motif Classification using Color-Texture-Based Feature Extraction and Backpropagation Neural Network," in IIAI 3rd International Conference on Advanced Applied Informatics, 2014, pp. 517-521.

[6] I. Nurhaida, A. Noviyanto, R. Manurung, and A. M. Arymurthy, "Automatic Indonesian's Batik Pattern Recognition Using SIFT Approach,” Procedia Comput. Sci., vol. 59, no. Iccsci, pp. 567-576, 2015.

[7] J. W. Yodha and A. W. Kurniawan, "Pengenalan Motif Batik Menggunakan Deteksi Tepi Canny Dan K-Nearest Neighbor," Techno Com, vol. 13, no. 4, pp. 251-262, 2014.

[8] H. Byun and S.-W. Lee, "a Survey on Pattern Recognition Applications of Support Vector Machines," International Journal of Pattern Recognition and Artificial Intelligence, vol. 17, no. 3, pp. 459-486, 2003.

[9] A. A. Kasim, R. Wardoyo, and A. Harjoko, "Feature Extraction Methods for Batik Pattern Recognition: A Review," in AIP Conference Proceedings, 2016, vol. 70008, pp. 1-8.

[10] I. Nurhaida, H. Wei, R. A. M.Zen, R. Manurung, and A. M. Arymurthy, "Texture Fusion for Batik Motif Retrieval System," Int. J. Electr. Comput. Eng., vol. 6, no. 6, pp. 3174-3187, 2016.

[11] Gaurav Mandloi, “A Survey on Feature Extraction Techniques for Color Images," Int. J. Comput. Sci. Inf. Technol., vol. 3, no. 3, pp. 14-18, 2013.

[12] M. Walid, M. Makruf, and Anwari, "Segmentasi Motif Batik Mengounakan Metode K-Means Clustering," in Seminar Nasional Humaniora Dan Aplikasi Teknologi Informasi (SEHATI), 2015, vol. I, pp. 2-5.

[13] Murinto and E. Ariwibowo, "Image Segmentation Using Hidden Markov Tree Methods In Recognizing Motif of Batik," J. Theor. Appl. Inf. Technol., vol. 85, no. 1, pp. 27-33, 2016.

[14] A. A. Kasim, R. Wardoyo, and A. Harjoko, "Feature Selection of Texture-Shape Batik Image with Information Gain in Motif Classification," in Third International Conference, SCDS 2017, 2017, pp. 106-115.

[15] D. P. Tian, "A review on image feature extraction and representation techniques," Int. J. Multimed. Ubiquitous Eng., vol. 8, no. 4, pp. 385-395, 2013.

[16] Mulaab, "Ekstraksi Fitur Motif Batik Berbasis Metode Statistik Tingkat Tinggi," in Seminar Nasional Informatika 2010 SEMNASIF, 2010, pp. 69-75.

[17] B. Arisandi, N. Suciati, and A. Y. Wijaya, "Pengenalan Motif Batik Menggunakan Rotated Wavelet Filter Dan Neural Network," JUTI, vol. 9, no. 2, pp. 13-19, 2011.

[18] A. H. Rangkuti, "Content Based Batik Image Classification Using Wavelet Transform And Fuzzy Neural Network,” J. Comput. Sci., vol. 10, no. 4, pp. 604-613, 2014.

[19] K. A. Nugraha, W. Hapsari, and N. A. Haryono, "Analisis Tekstur Pada Citra Motif Batik Untuk Klasifikasi KNN," INFORMATIKA, vol. 10, no. 2, pp. 135-140, 2014.

[20] V. S. Moertini and B. Sitohang, "Algorithms of Clustering and Classify ing Batik Images Based on Color, Contrast and Motif," in PROC. ITB Eng. Science, 2005, vol. 37, no. 2, pp. 141-160.

[21] A. A. Pratama, N. Suciati, and D. Purwitasari, "Implementasi Fuzzy C-Means untuk Pengelompokan Citra Batik Berdasarkan Motif dengan Fitur Tekstur," J. Tek. POMITS, vol. 1, no. 1, pp. 1-4, 2012.

[22] A. M. Arymurthy, "CBIRS pada aplikasi warisan budaya," 2011.

[23] Indah Soesanti and T. S. Widodo, "Batik Pattern Classification Based on Intelligent System," 2012. 
[24] A. A. Kasim and R. Wardoyo, "Batik Image Classification Rule Extraction using Fuzzy Decision Tree," in Information Systems International Conference (ISICO), 2013, no. December, pp. 2-4.

[25] A. A. Kasim and A. Harjoko, "Klasifikasi Citra Batik Menggunakan Jaringan Syaraf Tiruan Berdasarkan Gray Level Co- Occurrence Matrices ( GLCM )," in Seminar Nasional Aplikasi Teknologi Informasi (SNATI), 2014, pp. $7-13$.

[26] C. Xiang, Z. Yu, and X. Qu, "Support Vector Machine Optimized by Improved Genetic Algorithm," TELKOMNIKA Indones. J. Electr. Eng., vol. 12, no. 1, pp. 831-836, 2014.

[27] C. J. C. Burges, “A Tutorial on Support Vector Machines for Pattern Recognition,” 1997.

[28] A. S. Nugroho, A. B. Witarto, and D. Handoko, "Support Vector Machine "Teori dan Aplikasinya dalam Bioinformatika,"” in Proceeding of Indonesian Scientific Meeting in Central Japan, December 20, 2003, 2003.

[29] W. Y. Ling and Y. Hu, "Machine Learning to Design Full-reference Image Quality Assessment Algorithm," TELKOMNIKA, vol. 11, no. 6, pp. 3439-3444, 2013.

[30] F. Albregtsen, "Statistical Texture Measures Computed from Gray Level Coocurrence Matrices," Oslo, 2008.

[31] R. Haralick, K. Shanmugan, and I. Dinstein, "Textural features for image classification," IEEE Trans. Syst. Man Cybern., vol. 3, pp. 610-621, 1973.

[32] A. A. Kasim, R. Wardoyo, and A. Harjoko, "Batik Classification with Artificial Neural Network Based on TextureShape Feature of Main Ornament," I.J. Intell. Syst. Appl., vol. 9, no. June, pp. 55-65, 2017. 